\title{
The Development Trend and Countermeasures of Tourism in Fujian Province under the Belt and Road Initiative
}

\author{
Yaling Fu \\ Fuzhou University of International Studies and Trade, 350202
}

\begin{abstract}
The Belt and Road Initiative has positive influence on the development of many provinces and cities in China, for example, the Belt and Road Initiative promotes the development of tourism in Fujian Province, which is an important ecotourism province. This paper explores the development trend of tourism in Fujian Province under the Belt and Road Initiative, analyzes the current situation and existing problems of tourism service trade from the perspective of tourism brand building, types, popularization of high-speed rails. In order to promote the development of tourism in Fujian Province, this paper also proposes seven resolutions, such as optimizing industrial mechanism, perfecting planning and supervising mechanism, and combining the advantages of geographical position and tourism resource.
\end{abstract}

Keywords-The Belt and Road; Fujian Province; Tourism; Development trend

\section{INTRODUCTION}

Since President Jinping Xi put forward The Belt and Road Initiative in 2013 to 2015, National Development and Reform Commission and Ministry of Foreign Affairs jointly issued documents to promote the construction of The Belt and Road, analyzed the new opportunities of Chinese economic development and development situations of countries along The Belt and Road in the process of construction, proposed regional joint development policy and concepts to countries along The Belt and Road in order to promote the mutual beneficial cooperation and win-win with other countries. The Belt and Road Initiative plays an important role in promoting the development of many provinces in China. Especially the rapid development of service trades centered on tourism service trade, the current development of international tourism closely connected with soft power of culture of silk road. As an important ecotourism province, Fujian Province takes advantage of this policy and new opportunity, focuses on the development of tourism service industry, improve the provincial and regional economy by promoting the competitiveness of tourism industry. In this situation, the tourism of Fujian Province needs to explore the future development trend and find the correct way of tourism development.

\section{CURRENT Situation OF Tourism Service Trade IN FUJIAN PROVINCE}

\section{A. Numerous Famous Tourism Brands}

Since the development of tourism, Fujian Province has created numerous tourism brands, such as "Fresh Fujian Province", to publicize its tourism characteristics. A series of ocean theme tourism brands and high speed rail tourism brands have been created, which not only formed the tourism characteristics, but also improve the rapid development of tourism of Fujian Province. While the deep reformation is unrealized, the deep reformation is unrealized, which brings negative influence for the publicity of tourism brands.

\section{B. Abundant Travel Projects}

The tourism in Fujian Province centers on ecotourism. In the tourism projects, leisure rural tourism accounts for large proportion. Its varieties are more and more abundant for Fujian Province has developed a series of agritourism in rural areas, forests and fishing villages, and makes great efforts to publicize characteristic small towns and ancients towns and leisure cities and towns with local features, which have enriched the variety of tourism. In terms of red tourism, Fujian Province has been included in the "Hunan-Hubei-Fujian Province Red Tourism Zone" centered on Shaoshan, Jinggangshan and Ruijin. Led by Longyan City, five scenic spots have been selected as China's red tourist attractions, which are developing very rapidly and driving the development of other cultural tourism in Fujian Province. The abundant kinds of tourism is a double-edged sword. On one hand, it can promote the local economic development. On the other hand, if the development of tourism resources is not scientific, it is likely to constrain the local economic and environmental development of Fujian Province. Therefore, it is necessary to focus on this problem. 


\section{The Popularization of High Speed Rail Drives the Tourism Development}

With the continuous improvement of China's transportation system, more convenient new modes of transportation are widely used, which provide great convenience and more choices of traffic modes for people's lives. In particular, the rapid development of high speed rail has reduced the spatial distance between cities, and has greatly reduced the travel time of passengers. The range of travel has been continuously expanded. Fujian Province is a great beneficiary of the development of high-speed rail. With the continuous improvement of high speed railways, many famous scenic spots have more tourists coming from distant places. For example, after the operation of the Hefei High Speed Railway, the tourists of Taimu Mountain, Wuyi Mountain, Yongding Classic Earth Building and other scenic spots have expanded from tourists coming from Fujian, Jiangsu, Zhejiang, Guangdong and other neighboring provinces to places such as Beijing, Shandong, Hebei. For foreign tourists, with the development of high speed rail, in addition to classic international tourist cities such as Beijing, Shanghai, Shaanxi, Sichuan and Tibet, they have more choices, such as Fujian Province. The formation of the high-speed rail travel circle brought many opportunities, but also more challenges causing from the diversification of the passenger sources. Especially for the service industry, the comprehensive planning and correct guidance to better take the opportunities and solve the problems brought by popularization of high speed rail tourism.

\section{The Status of Tourism Industry Has Been Improved}

In recent years, in the process of economic development, the Fujian Provincial Government has made great efforts to support the development of the tourism industry, increase the investment, continuously improve the relevant infrastructures, and carried out the construction and transformation of the ecological environment, etc. All measures make tourism occupy an increasingly important position in the economic development of Fujian Province. The development of tourism would optimize the city image and attract more foreign tourists. However, the influx of a large number of non-native populations will also bring a series of derivative problems, such as tourism safety, urban security, environmental disruption, etc. It may have an adverse impact on the city image. Therefore, the tourism industry in Fujian should take more management responsibilities.

\section{STRENGTHS OF TOURISM DEVELOPMENT IN FUJIAN}

\section{A. Abundant Tourism Resources Along Maritime Silk Road}

Fujian is the important birthplace of ancient Maritime Silk Road and core area of Maritime Silk Road of 21st Century. Therefore, Fujian has diversified tourism culture. At present, Fujian still retains docks, ports, religious temples, architectural sites, etc. related to the construction of Maritime Silk Road in different historical periods. It also has a rich historical content of Mazu culture, religious culture, Fujian merchant culture and shipping culture. Zheng He has left many valuable cultural tourism resources in Fujian during his travelling to the west, which created a rich material and intangible cultural heritage in
Fujian. The maritime Silk Road culture and tourist sites which promoted the overall cultural tourism construction in Fujian have been well protected and developed, such as Taiping Port in Changle, Fuzhou which play an important role on the Maritime Silk Road and Quanzhou, the first "large port in the East", which was officially recognized as the starting point of the Maritime Silk Road by UNESCO.

\section{B. Advantages of Geographic Position and Chinese and Overseas Chinese Resources}

Fujian Province is located in the southeast coastal area of China. Fujian has tortuous coastline, numerous islands, excellent harbors, unique geographical position and natural resources superiority. It has been an important channel for the Maritime Silk Road since ancient times and is also an important place for foreign trade development. At the same time, as Fujian is located in the coastal area, it gave birth to a unique maritime culture, which created the excellent quality of "no pain, no gain" of Fujian people. Fujian people is the main force in the early development of overseas markets in China, which made Fujian become an important hometown of overseas Chinese, and most of the overseas Chinese in Fujian are concentrated in Southeast Asian countries along the Belt and Road. Fujian has attached great importance to exchanges and contacts with overseas Chinese all the time. In the process of tourism development, Chinese overseas Chinese have also brought strong financial support. With the introduction and implementation of The Belt and Road Initiative, more and more Fujian overseas Chinese have been attracted to explore and develop Fujian tourism resources to promote the development of tourism industry in Fujian.

\section{Convenient Transportation}

Convenient transportation plays an important role in the development of tourism. Fujian pays much attention on the construction of traffic system. The comprehensive development of land, sea and air transportation means has been established, and the construction of high speed rail, bullet train and expressway are basically completed. In recent years, Fujian expanded many large airports and greatly increased number of domestic and international flights. The traffic system in Fujian has developed comprehensively with large accessibility and connectivity. The convenient transportation also drives the development of tourism and attracts more tourists.

\section{COUNTERMEASURES OF TOURISM IN FUJIAN PROVINCE UNDER THE BELT AND ROAD INITIATIVE}

\section{A. Optimize Tourism Industry Mechanism}

Under the perspective of The Belt and Road, the standard and stable tourism industry mechanism is important to giving full play of abundant tourism resources and tourism brands. Therefore, it is important to optimize the tourism industry mechanism to further develop the tourism industry in Fujian. The established unified tourism industry management mechanism led by government would efficiently manage the tourism industry and tourism resources. It is important to strengthen government intervention and guidance to manage the tourism market, formulate series of standards and 
requirements for the development of tourism industry. In addition, the government shall establish large tourism service enterprise to guarantee the tourism service quality and build a justified and harmonious tourism market and policy environment.

\section{B. Improve Tourism Industry Planning and Supervision Mechanism}

The proposal and implementation of the Belt and Road has accelerated the development of tourism in Fujian Province. For the problems arising from rapid development, it is necessary to build a completed tourism industry planning and supervision mechanism in order to make good use of the policy which shall be the driving force for the steady and rapid development of Fujian's tourism industry. Therefore, in the process of tourism development, it is necessary to specify the development process, comprehensively supervise the implementation of each link, timely find out and correct the problems causing in the implementation process to ensure the mutual cooperation and mutual benefit with related industries and to promote and ensure the healthy development of the tourism industry.

\section{Improve the Management Level of Tourism Industry}

The development of Tourism industry, one of important service industries in Fujian, has great influence on the whole economic development of Fujian. Especially after proposal of The Belt and Road Initiative, more and more foreign tourists travel in Fujian. Therefore, it is important to improve the overall development level and service level of tourism industry, to improve its competitiveness and specify the related standards and requirements. The government shall establish a completed tourism industry standards and supervision standards to supervise the practitioners of tourism industry, to promote integrity management, to protect the city image of Fujian and avoid actions violating laws and regulations.

\section{Strengthen the Introduction of Foreign Capitals}

Fujian has prosperous ecotourism. Tourism is an important pillar in the economic development of Fujian Province. With the implementation of The Belt and Road, Fujian Province needs to continue to develop tourism industry and establish a new development mode driven by tourism projects. The government needs to invest more capitals and attract foreign capitals of countries along The Belt and Road to develop and utilize the tourism resources giving full play of unique overseas Chinese resources, to develop the standardization and industrialization development of tourism industry, and further drive the harmonious development of other industries.

\section{E. Improve the Infrastructure Construction}

It is important to improve the infrastructure construction with the development of tourism industry, the popularization of high speed rail and The Belt and Road Initiative. The infrastructure construction of all important scenic areas shall be further invested according to passenger flow volume. The means of transportation which connect scenic spots, main sites and hotels shall be completed. The public utilities and environment around scenic spots shall be further developed to meet the requirements of tourists. Apart from the construction of infrastructure, it is also important to develop the culture of scenic spots by integrating local features of customs and habits based on its original cultural connotation.

\section{F. Improve the Reasonable Exploitation and Protection of Tourism Resources}

Fujian has abundant tourism resource and tangible and intangible cultural heritages. In order to actively respond to The Belt and Road Initiative and promote the development of tourism industry, it is necessary to reasonably develop and protect tourism resources. In the process of tourism development, it is necessary to take bearing capacity into account, to formulate a series of protective measures and systems, coordinate the relationship of tourism resource protection and economic development and avoid damaging tourism resources. Fujian has plenty of large ports and wharf. The ecological environmental protection is important to avoid water and soil pollution, destruction of the ecological environment and to protect the tourism brand of "Fresh Fujian".

\section{G. Improve the Overall Quality of Tourism Talents}

For the diversified passenger sources under The Belt and Road Initiative, in order to provide high-quality service and meet the needs of tourists, industry service industry needs kinds of high-quality talents to in item design, e-commerce and marketing, etc. Therefore, Fujian shall make great efforts in cultivating qualified management personnel, reinforce the integration of related courses design and assessment with the policy of The Belt and Road. Furthermore, related government organs shall further improve occupational requirements examination system and training system and regulate that new Tourism Law shall be the important guidance of training the tour guides, etc. The talents could inject new vitality to tourism industry, provide humanistic quality and optimize the image of Fujian.

\section{CONCLUSION}

The Belt and Road Initiative proposed new development direction for economy development in China and surrounding countries, and have great influence on the future development of tourism in Fujian Province. It is necessary to clarify the strengths and weaknesses of development, find the correct way to optimize tourism industry meachnism, amplify tourism industry planning and supervisory mechanism, improve the management level, promote overall quality of tourism professionals to promote the sound development of tourism in Fujian Province. Devote greater effort to introduce foreign capitals, improve and complete infrastructure construction and exploitation and protection of tourism resources. The Belt and Road would promote steady development and provide more opportunities for tourism in Fujian Province. 


\section{REFERENCES}

[1] Lingyun Zhang. Written Discussions on China's Tourism Development-The Belt and Road and Tourism Development in Chian (2)[J]. Tourism Tribune, 2017,32(06):1.

[2] Jie Feng. Countermeasures of Tourism Development of Fujian Province under the Perspective of The Belt and Road[J].Times Finance, 2017(27):73-74.

[3] Xiangnong Yi. Improve Red Culture Protection, Inheritance and Development by Red Tourism-Research on red resource protection and red tourism development in Fujain[J]. Fujian Province Dangshi Yuekan, 2016(12):31-34.

[4] Jin Chen, Jing Sun. Impact Analysis of of Tourism in China in HighSpeed Rail Times[J]. Tourism Overview (The 2nd Issue of the Month), 2016(07):184+186.

[5] Mengying Zhu. Study on the Construction of Fujian Province Tourism Corridor Hester Cultural Heritage Road[J]. Journal of Guangxi Economic Management Cadre College,2018,30(01):49-56.

[6] Jianbiao Zhou.Developing Marine Silk Road Culture Tourism Core Booster Maritime Silk Road Construction[J]. Journal of the Party School of CPC Xiamen Committee, 2016(04):11-16.

[7] Guocan Huang, Zehua Jiang. Research on the Innovative Development of Tourism in Xiamen under The Belt and Road Initiative [J].City,2017(07):32-35.

[8] Yuefeng Luo. Research on the Development Route of Fujian Province Sports Tourism in the Background of the Belt and Road Initiative[J]. Journal of Fujian Province Commercial College,2018(01):57-61. 